\title{
Current trends in the exploitation of mature gas fields in the context of rehabilitation concept
}

\author{
Diana $\operatorname{Lupu}^{1,2 *}$ \\ ${ }^{1}$ Petroleum Gas-University of Ploiești, Avenue Bucharest, no. 39, Ploieşti, Romania \\ ${ }^{2}$ The National Gas Company Romgaz SA, I.C.Motas 4 Square, Medias, Romania
}

\begin{abstract}
The exploitation of mature natural gas fields has been and will be an increasingly topic that will attract the attention of the production companies, given that most of the production, about $60-70 \%$, comes from these reservoirs. Implementation of the project management into the exploitation of mature gas reservoirs has a notable ascension because of the fact that in the execution of the operational programs always has developed a mechanism to achieve the objectives in a sustainable manner. The project management in gas industry it is known as rehabilitation concept or integrated reservoir development, which has a major impact on increasing the recovery factor. The paper intends to present the current trends in the exploitation of mature gas fields in Romania by applying the concept of rehabilitation as well as expansion opportunities in order to drive the business performance results.
\end{abstract}

\section{Defining elements of mature gas reservoirs and the rehabilitation concept}

Mature fields or brownfields are those hydrocarbon reservoirs characterized by an advanced stage of reservoir pressure depletion, have difficulties and various operational challenges such as blockages of the productive layers, liquid loading, sand production, high water rates etc. Also, mature fields, after decades of exploitation, are characterized by difficulties and / or challenges related to the exploitation of surface facilities in the sense that the equipment can have a high degree of wear which can generate a lower operating safety level.

Analysing the qualitative graph of productive life cycle of a gas reservoir (Figure 1), it can be seen that mature fields no longer fall in the areas II and III (known in the literature as "peak production" or "plateau production" - productive period of reservoir that highlight the increasing trend and production stability), but fit into the area where declining production trend is beginning to register (zones IV, V and VI).

The "maturity" stage of natural gas reservoirs has a particularly correspondent in the exploitation activity, as the productive potential of these reservoirs can be still tempting in terms of the economic benefits.

Continuing the exploitation of the natural gas reservoirs which have reached the maturity stage it means to face many and complex challenges but there are still a number of viable

\footnotetext{
${ }^{*}$ Corresponding author: diana.lupu@romgaz.ro
} 
options that can be considered and applied successfully to reduce the decline rate, extending the life cycle, which ultimately leads to maximization of recovery factors.

One of the ultimate options for maximizing the recovery factor is the so-called rehabilitation concept. The rehabilitation of mature fields is carried out on those reservoirs that have produced for a long time, have a representative production history and from which are still expecting important production volumes and economic benefits. [1]

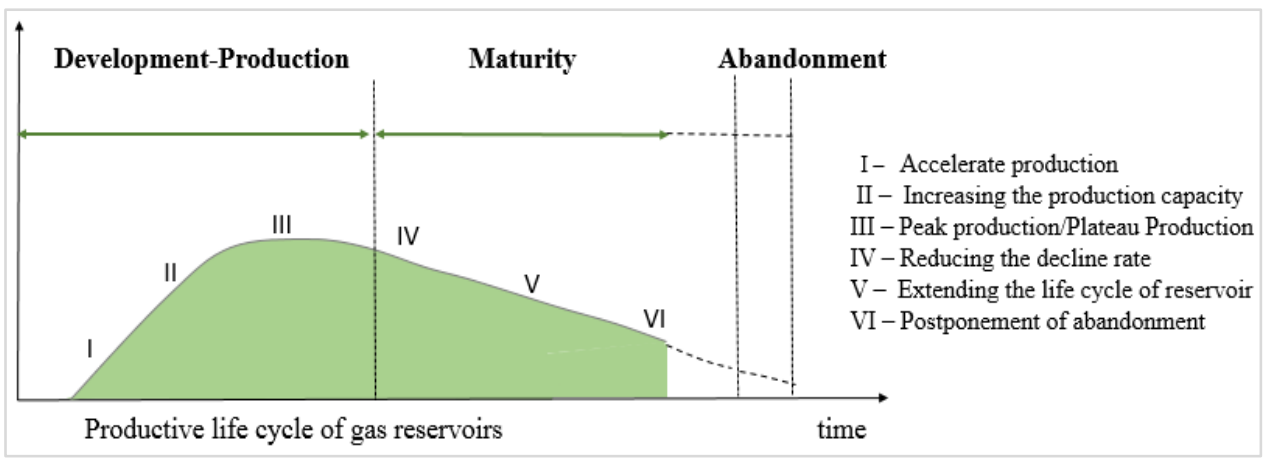

Fig. 1. Graphical representation of the productive lifecycle of a gas reservoir

When analysing Figure 1, it is recommended that the implementation of the rehabilitation concept be around the IV-V transition zone, during the period when the production of the reservoir has a decreasing trend and the production decline is becoming more pronounced.

Prior to implementing the rehabilitation concept, the specialized departments of a hydrocarbon producing company must go through a precursor stage that aims to identify those candidate fields to rehabilitation process.

Figure 2 shows a comprehensive diagram with the stages preceding / selecting procedure for the brownfields which may become candidates to rehabilitation process.

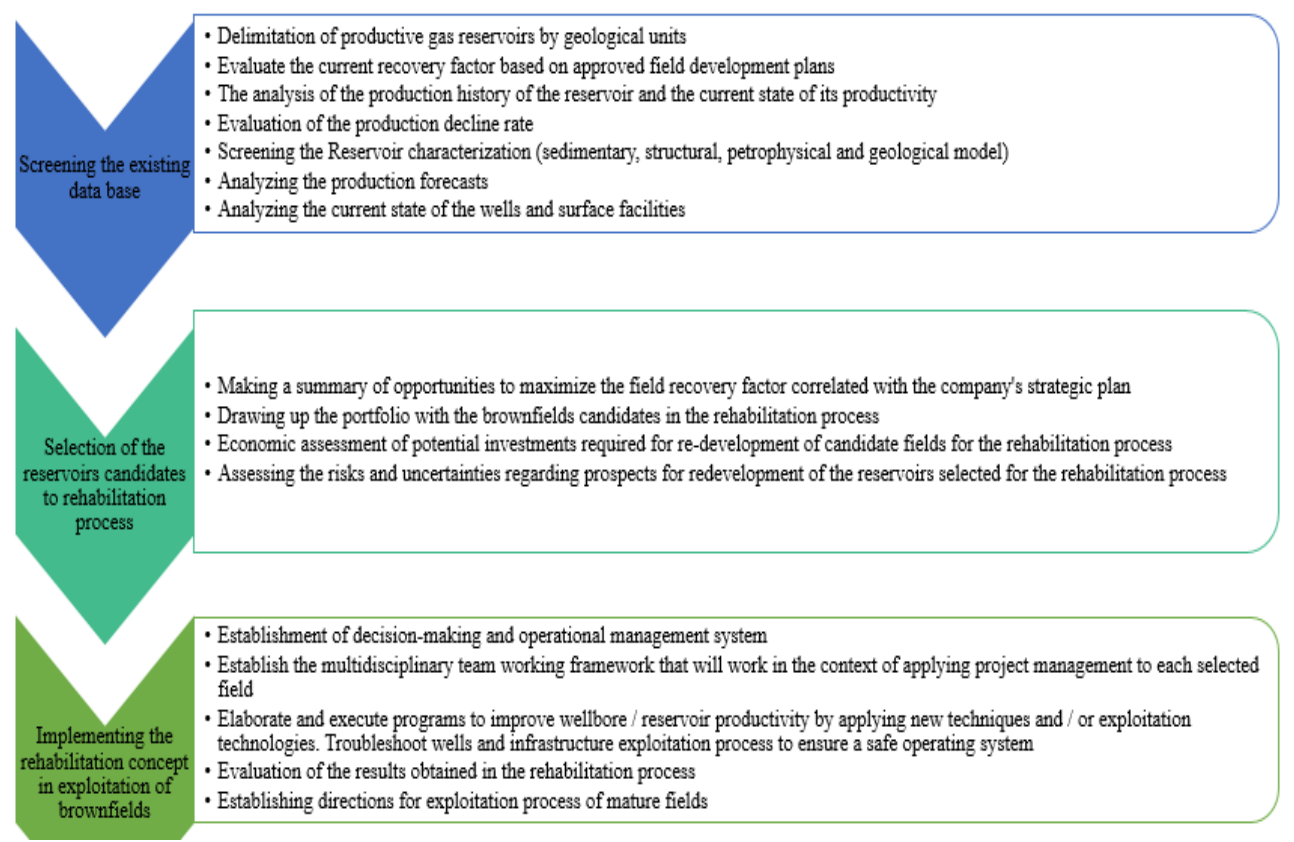

Fig. 2. Diagram of the selection stages of the brownfields for the rehabilitation process 


\section{Project management through the concept of rehabilitation of mature gas reservoirs}

The implementation of project management in the oil and gas industry was a result of the fact that in the implementation of the operational programs a project management was systematically developed aiming to improve the decision making process and the overall execution of the operation, and had five stages: evaluation, planning, execution and control [2].

The process of mature field rehabilitation it takes the form of project management, so the term "rehabilitation project" will be used.

Each project is unique, but the management of each project must follow the following sequence:

- The team defines the objective to be achieved, including prioritization, identification of technology and expertise, setting the expected quality levels, requirements related to the safety and cost-effectiveness of operations.

- Budget allocation, allocation of expenditure responsibilities and how to address them.

- A strategy for fulfilling the tasks needs to be established. It is important to anticipate all the events and make contingency plans for the unexpected deviations that often occur.

- Work planning should be planned to ensure the integration of all tasks.

- A tracking and control system must be developed to ensure that the project progresses in line with the planning by measuring the actual work done on the program.

- The project must be closed, which includes checking the status of all the intended objectives to be met to ensure that the project is completed to an acceptable level of quality [3].

Identifying and allocating human, material, financial and informational resources is an indispensable activity of the project. At the beginning of the project, a multidisciplinary team of specialists such as geologists, geophysicists, petrophysicists, reservoirs engineers, production engineers, economists and other support specialists is being set up, creating an appropriate working environment by providing working tools specific to production engineering, reservoir engineering, completion, drilling, geology, geophysics, management, accounting, information technology, safety and environmental protection etc.).

The sequences or phases of a rehabilitation project are those of the classic / traditional approach (related to any type of project).

Starting from these sequences and considering the specific activities related to the exploitation of hydrocarbon reservoirs, figure 3 presents a scenario setting out the phases of the project management from the point of view of the rehabilitation of the mature gas fields.

The field development plan (FDP), besides the fact that it is the reference documentation on which the oil and gas operations are carried out on the exploitation-production perimeters taken into concession, is a control tool for the exploitation of natural gas reservoirs. The development plan is the document that substantiates the quantity and quality of geological resources and reserves, which is confirmed / approved by the competent authority, according to the national oil and gas legislation.

An important document in rehabilitation projects is it the annual work program (WP), which contains in a detailed form the programs of operations to be executed in the next year and the necessary budget. Compared to the FDP, the work program has a much more detailed structure and is an internal document of the rehabilitation project, but it includes the operations foreseen in the development plan that are priority, but also other additional operations with the scope of capitalizing the reserves and increase the recovery factor. 


\begin{tabular}{|c|c|c|c|c|}
\hline \multicolumn{5}{|c|}{ Phases of project management from the perspective of the rehabilitation of mature gas fields } \\
\hline $\begin{array}{l}\text { Initiation of the } \\
\text { rehabilitation project }\end{array}$ & $\begin{array}{l}\text { Planning / Development of the } \\
\text { rehabilitation project of the } \\
\text { reservoir }\end{array}$ & $\begin{array}{l}\text { Execution / Run the } \\
\text { rehabilitation project }\end{array}$ & $\begin{array}{l}\text { Control and monitor the } \\
\text { results obtained in the } \\
\text { rehabilitation project }\end{array}$ & $\begin{array}{l}\text { Completion/Closing the } \\
\text { rehabilitation project }\end{array}$ \\
\hline $\begin{array}{l}\text {-Establishing the objectives } \\
\text { of the project for the } \\
\text { rehabilitation of the reservoir } \\
\text { and expected results (project } \\
\text { outcome) } \\
\text {-Determining the duration of } \\
\text { the rehabilitation project } \\
\text {-Identifying the resources } \\
\text { needed to run the project } \\
\text {-Developing the } \\
\text { multidisciplinary team } \\
\text {-Estimate the cost and } \\
\text { prepare the budget needed to } \\
\text { initiate the rehabilitation } \\
\text { project }\end{array}$ & $\begin{array}{l}\text {-Elaboration of the field } \\
\text { redevelopment plan for a } \\
\text { minimum of } 5 \text { years and the } \\
\text { work programs } \\
\text {-Identifying constraints } \\
\text {-Development of the WBS- } \\
\text { Work Breakdown Structure } \\
\text { activities } \\
\text {-Elaborating the timetable with } \\
\text { the activities related to the } \\
\text { program } \\
\text {-Estimation of costs and budget } \\
\text { planning } \\
\text {-Preparation of the management } \\
\text { plan (decision, quality, risks, } \\
\text { training, communication, } \\
\text { security and safety, information, } \\
\text { procurement, contracts, results } \\
\text { etc.) }\end{array}$ & $\begin{array}{l}\text {-Application of the FEL (Front- } \\
\text { End-Loading) and DSO } \\
\text { (Decision Scenario Option) } \\
\text { methodology in all work } \\
\text { programs aimed to achieve the } \\
\text { objectives of the rehabilitation } \\
\text { project } \\
\text { - Increase of the RESERVOIR } \\
\text { productivity through the } \\
\text { operational programs } \\
\text { (productive layer-wells-surface } \\
\text { facilities) } \\
\text {-Implementation of new } \\
\text { technologies and } \\
\text {-Implementing and improving } \\
\text { safety system and the } \\
\text { environment protection system }\end{array}$ & $\begin{array}{l}\text {-Monitoring the status of the } \\
\text { proposed objectives in the } \\
\text { rehabilitation project versus } \\
\text { plan } \\
\text {-Monitoring costs and budget } \\
\text {-Measuring the performance } \\
\text { and progress achieved in the } \\
\text { project } \\
\text {-Analyzes and reports } \\
\text {-Identification of deviations } \\
\text { and risks } \\
\text {-Risk correction / mitigation } \\
\text { measures } \\
\text {-Authorization system } \\
\text {-Management of project } \\
\text { changes }\end{array}$ & $\begin{array}{l}\text { - Administrative closure of } \\
\text { the project (verification and } \\
\text { documentation of the } \\
\text { results of the rehabilitation } \\
\text { project (archived, reusable), } \\
\text { analysis of project success } \\
\text { and benefits } \\
\text { - Closing of the contract (if } \\
\text { applicable) } \\
\text {-Handover of final report to } \\
\text { stakeholders (partners / } \\
\text { customer-beneficiary, etc.) }\end{array}$ \\
\hline
\end{tabular}

Fig. 3. Phases of project management from the perspective of mature gas field rehabilitation

The work programs should generally include the following:

- Remedial programs for the difficulties of exploiting the reservoir for the immediate period in which concrete actions are taken to reduce the rate of decline and to improve the productivity of the wells in order to achieve the objectives of the rehabilitation project (workovers, well completion, production stimulationacidizing, re-perforation under balance, fracturing, modernization of surface facilities, installing compression etc.)

- Program for assessing the potential of the reservoir for both productive and bypassed or even undiscovered layers. This program may include seismic data acquisition, geophysical investigations, geological studies and detailed field engineering, field research, laboratory research and experiments etc. In practice, the additional evaluation program aims to acquire new data leading to new work programs to be carried out within the rehabilitation project.

- The budget required to carry out all the works to increase the productivity and the reservoir evaluation program, is broken down into operating expenses and capital expenditure (OPEX and CAPEX).

Each annual work program and annual budget is structured on a quarterly basis and includes the details of the proposed oil or gas operations, including all relevant data and information, the estimated cost, the duration of each operation, the estimated monthly average production.

The annual work program and budget, including the production program of the reservoir, are prepared by the project team and the project manager must present and submit for approval to the management committee of the rehabilitation project (established in the preproject phase). The annual work program should be approved by the fourth quarter of the current year at the latest in order to effectively implement it.

Finally, the work program is a specific tool for project management in the context of the rehabilitation of gas brownfields that should be update in annually basis.

It is very important to identify from the beginning, but also throughout the project, constraints or restrictions that may condition or limit the development plan and work programs. Constraints are in principle resource and time-related, but once identified, a 
contingency plan is created to avoid unexpected situations and to manage risks effectively (part of the risk management plan).

The rehabilitation project requires the development of a detailed structure of the activities of the project: production, engineering, geology, drilling, supervision, procurement, accounting, safety and environmental protection.

Such organizational structure is a key instrument in the project's rehabilitation project, known in the field of project management as the "Work Breakdown Structure (WBS)", and aims to divide the project into segments of activities to facilitate the planning process, budget estimation, execution, authorization, reporting of the performance of the project etc.

To exemplify what is a WBS, in Figure 4 has developed a WBS scenario for drafting the work program and budget for the rehabilitation project of a mature gas field.

In other words, a detailed structure of activities (WBS) within the rehabilitation project means organizing the work in an effective way that is relatively easy to monitor and control, while at the same time empowering the members of the project team to perform their work tasks.

The WBS can be applied across to all programs, even at smaller scale, so that by dividing a task into detailed components, a good organization and efficiency of work is achieved that ultimately leads to the achievement of objectives.

The management plan is a specific project management tool and has several divisions:

- Decision Plan / Stakeholders plan

- The communication plan

- Risk Management plan

- Change management plan

- Quality plan and Procurement plan

- Control plan.

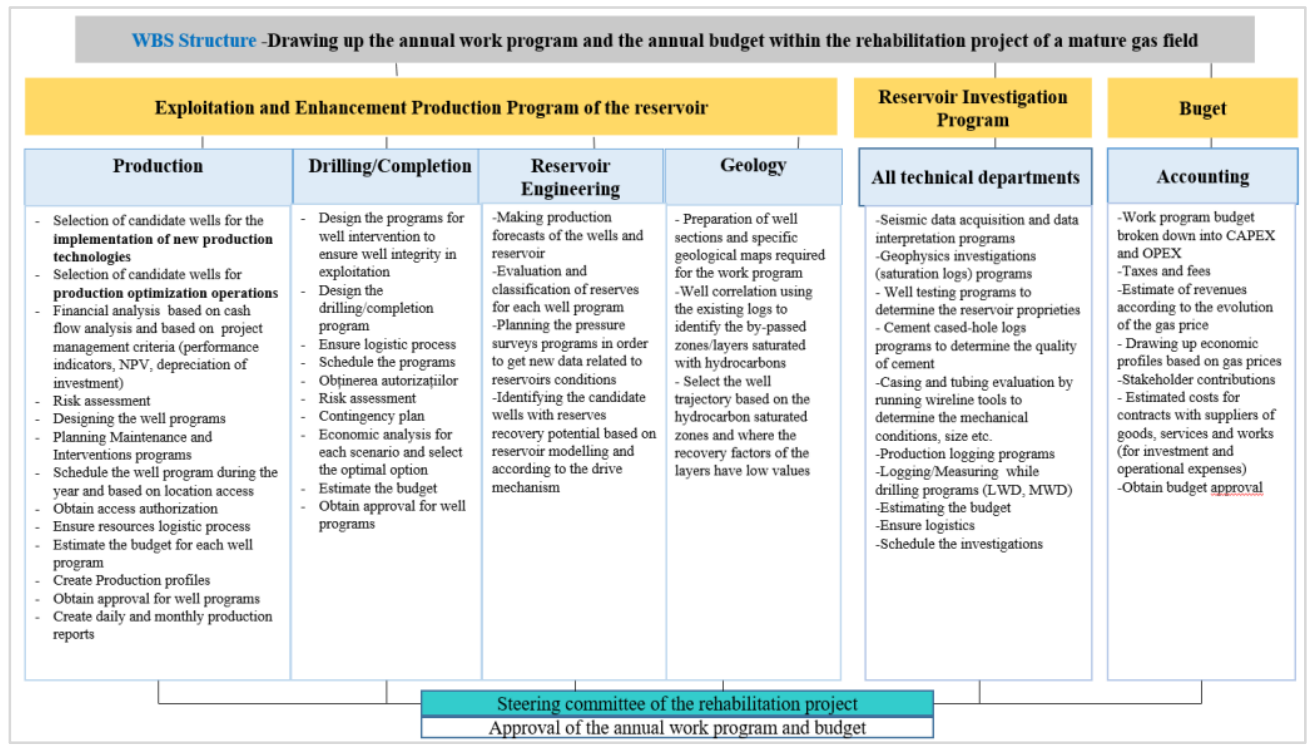

Fig. 4. Example of a WBS scenario when developing the annual work program and budget under the rehabilitation project of a mature gas field

Financial engagements in petroleum operations have long since begun to rely on a continuous improvement system, namely the application of the so-called Front-End-Loading (FEL) methodology. 


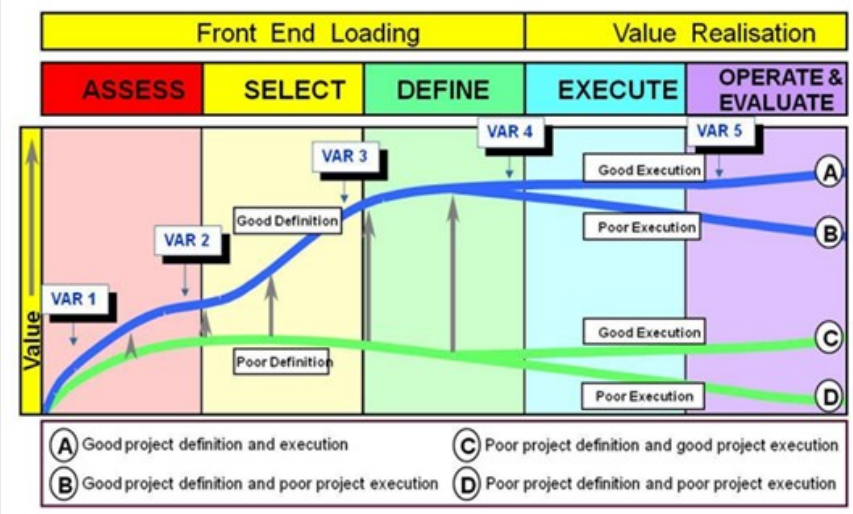

Fig. 5. Front-End-Loading methodology [4]

The application of the FEL concept in the development of rehabilitation projects, more precisely in the programs that are design to increase the productivity of the mature reservoirs offers several advantages, as follows: reduce the duration / timing of the program, generation of values-cutting costs and time, improving quality and improving communication, the use of human resources, allocation of resources and expected results, decision making, responsibility, technical innovation and quality of work, early incremental production, economic value.

\section{Improving the productive performance of gas reservoirs by implementing the concept of rehabilitation}

\subsection{Key performance indicators}

Improving the productive performance of a mature natural gas field refers to the rehabilitation of its entire commercial reservoir (productive zones and associated surface facilities) in order to achieve three major objectives:

- Maximizing recovery factor

- Reducing the decline rate

- Increase in reserve replacement rate.

The performance of the reservoirs, respectively the final recovery factor, is largely dependent on the existing energy types in the reservoirs that allow the fluid to flow from reservoir to the well. The forms of energy predominant in natural gas fields are those of gas expansion and aquifer expansion.

If the recovery factors of reservoirs for gas expansion drive mechanism can reach values up to $80-90 \%$, the situation is far more unfavourable in the case of water-drive mechanism (through the expansion of the adjacent aquifer), where statistically has observed that recovery factors rarely exceed $50 \%$. This is due to the inflow of water into the reservoir and the change in relative permeability that lead to the reduction of gas production. In addition, if the productive layer consists of sandy-clay intercalations with low permeability, the gas recovery in that formation is significantly reduced.

Analysis of declination curves is a graphical method that allows forecasting of production and estimating the reserves. Knowing that mature hydrocarbon reservoirs, in particular, the gas reservoirs are characterized by production decline, the major interest is to minimize or reduce the decline rate. 
The decline rate is a parameter that gives us information about how the reservoirs were exploited and how we need to act forward. Achieving a maximum recovery factor is dependent on reducing or minimizing the decline rate.

Any gas producing company calculates and updates its annual reserves replacement rate (R) using the following formula:

Where:

$$
R=\frac{G_{p r}+G_{n}}{\Delta G}
$$

$\mathrm{G}_{\mathrm{pr}}$ - increase of proven gas reserve as a result of reassessment of the reservoir productive potential

$\mathrm{G}_{\mathrm{n}}$ - increase in proven gas reserves from new discoveries (explorations)

$\Delta \mathrm{G}$ - total gas production for the respective year

This indicator $\mathrm{R}$ is undisputed, primarily related to the exploration activity, and then to the exploitation and rehabilitation of brown fields [5].

\subsection{Current trends of exploitation of mature gas fields at international and national level}

The concept of redevelopment / revitalization of hydrocarbon reservoirs has begun to be applied quite recently in the oil and gas industry as a result of the fact that in recent years the industry has begun to face complex challenges and changes that increased the exploration and development costs combined with fluctuations in oil prices or gas demand.

Therefore, there has been a growing interest in capitalizing the mature fields and maximizing the potential of these energy accumulators. The redevelopment of mature hydrocarbon reservoirs is more tempting for hydrocarbon producers after an analysis showed that a $1 \%$ increase in the recovery factor could result in two more years of global added volumes oil and gas. In addition, at global level, is estimated that $70 \%$ of oil and gas production comes from mature fields, which means that all hydrocarbon producers have $70 \%$ depleted reservoirs in their portfolio. [6]

This global trend, combined with the dynamics of oil and gas market prices, has led hydrocarbon producers, especially in recent years, to have a different approach in exploitation of mature fields.

The activities of exploitation of the brownfield has increased both in the offshore and onshore fields and the prerequisites for the extension of this rehabilitation concept are inevitable because this concept of exploitation is the ultimate option of improving the productive performance of the reservoirs.

At international level, since 2004, several oil and gas operators started to implement the rehabilitation concept under the form of production enhancement contracts, petroleum sharing contracts, petroleum sharing agreements with specialized services companies which have expertise, technology and highly qualified personnel in field re-development. Such examples are:

- Petronas Carigali Sdn Bhd (PCSB) started in 2004 the re-evaluation of reservoir potential and effectively in 2010 started the implementation of rehabilitation of the offshore oil reservoir Samarang, Malaysia-Est, for 10 years partnership with Schlumberger. [7]

- In October 2009, Zubair's oil and gas field (onshore) in Iraq was the reason for a twenty year partnership between Eni (32.81\%), Oxy (23.44\%), KOGAS (18.75\%) and Missan Oil Company (25\%) to re-develop he field. [8]

- In 2012, Shushufindi, one of the largest oil fields in the Oriente basin in Ecuador, implemented the rehabilitation concept as a result of the Ecuadorian government's 
risk of falling oil revenues. The redevelopment plan is scheduled for 15 years by the Consorcio Shushufindi Partnership. [9]

- In 2018, Royal Dutch Shell (Shell) announced the decision to invest in the redevelopment of the North Sea-UK Penguins oil and gas field. [10]

Here were presented a few examples to highlight the recent or current trends in the exploitation of oil and gas brownfield, both offshore and onshore, which at the same time indicates the prospects of extending the rehabilitation concept in the future to a wider scale.

Romania ranks among the first countries at the international level which implemented the concept of rehabilitation, in the sense that the first rehabilitation project started in 2003 on the Laslau Mare mature gas field, Mures County, located in the Transylvanian basin. This project started as a partnership between The National Gas Company Romgaz and Schlumberger.

The results obtained within Laslau Mare Project over 15 years of partnership were the real premise for Romgaz company, between 2015-2016, to start others rehabilitation projects, (organized at the company's internal level) on eight gas brownfields (seven of them are located in Transylvanian Basin and one of them is located in Moldavian platform).

Currently, the additional production represents about $12 \%$ of Romgaz's total production, taking into account that there are more than one hundred commercial gas reservoirs in the company's portfolio. The additional production is brought through the annual works and the implementation of new production technologies, drilling, well maintenance, and completion programs, all of them being executed under the rehabilitation projects.

Also, another major operator in Romania, OMW Petrom, in 2010, signed a Production Enhancement Services Agreement with Petrofac to further develop and improve production in the Ticleni area on nine oil reservoirs (Gorj County). The contract was run for 5 years and then OMW Petrom took over the exploitation and continued the rehabilitation works [11].

In 2013, the same company has announced that will start the re-development of Suplacu de Barcau oil field (Bihor County) and the investments are significantly [12].

In 2014, Tazlau oil field located in North-Easter Romania, Bacau County, was the reason of significant investments for redevelopment and increasing the portfolio of rehabilitation projects developed by OMW Petrom.

As it can be observed, the current trends in the exploitation of mature gas and oilfield at national and international level are focusing on implementation of rehabilitation concept as a result of the fact that the producing companies are aware of the valuable potential still held by the mature reservoirs.

\section{The way forward into the exploitation of mature gas fields by extending the implementation of rehabilitation concept}

The extension of the concept of rehabilitation is a very important aspect that should be considered in the further exploitation of natural gas fields whose depletion stage is advanced.

If the exploitation of the natural gas reservoirs located in Transylvanian basin under the rehabilitation projects generated good practices that can be extended to other gas reservoirs located in the same geological unit, the situation of exploitation in the extra-Carpathian area of Romania is much more complex.

Difficulties in the exploitation of natural gas reservoirs in the extra-Carpathian area are mainly represented by the drive mechanism. Water drive mechanism is predominant as a form of energy therefore the mainly challenges are low recovery factors, but also sand production.

Due to the complex exploitation problems, the extension of the concept of rehabilitation to mature natural gas fields in the extra-Carpathian area is imperative, considering the market demand for natural gas in that area of consumption and also the valuable energy held in those 
reservoirs. New approach of exploitation may be required such of perforation techniques, completion design, stimulation design, number of wells put into production according to the geological models.

Particular attention must be paid to the way in which the wells are put into production at the geological objectives correlated with the aquifer model adjacent to the reservoir in order to delay water influx in the saturated gas layers.

An approach more careful of water-drive reservoirs can only be achieved in the context of the implementation of the concept of rehabilitation, and the reasons are more pronounced according to the statistical analysis that was made on a total number of 39 mature natural gas fields from the extra-Carpathian area presented in Table 1 and Figure 6 which illustrates the value of the current recovery factors on the three analysed geological units.

The same analysis highlights the need for re-evaluation of resources and reservoirs based on new investigations that have brought additional information that can contribute both to the re-configuration of the geological model and to the future design of the exploitation.

Simulation of production behaviour and water influx of adjacent aquifers can provide valuable information that can be used also as arguments for the implementation of new practices and production technologies.

Table 1. Statistical analysis of current recovery factors of natural gas reservoirs on the ExtraCarpathian area

\begin{tabular}{|c|c|c|}
\hline Geological Unit & $\begin{array}{c}\text { Reference number of } \\
\text { gas reservoirs for } \\
\text { statistical analysis }\end{array}$ & $\begin{array}{c}\text { Average of current } \\
\text { recovery factor [\%] }\end{array}$ \\
\hline Getic Depression & 11 & 56.60 \\
\hline $\begin{array}{c}\text { Moesian Platform (Center-North- } \\
\text { East) }\end{array}$ & 13 & 58.92 \\
\hline Moldavian Platform & 15 & 64.31 \\
\hline
\end{tabular}

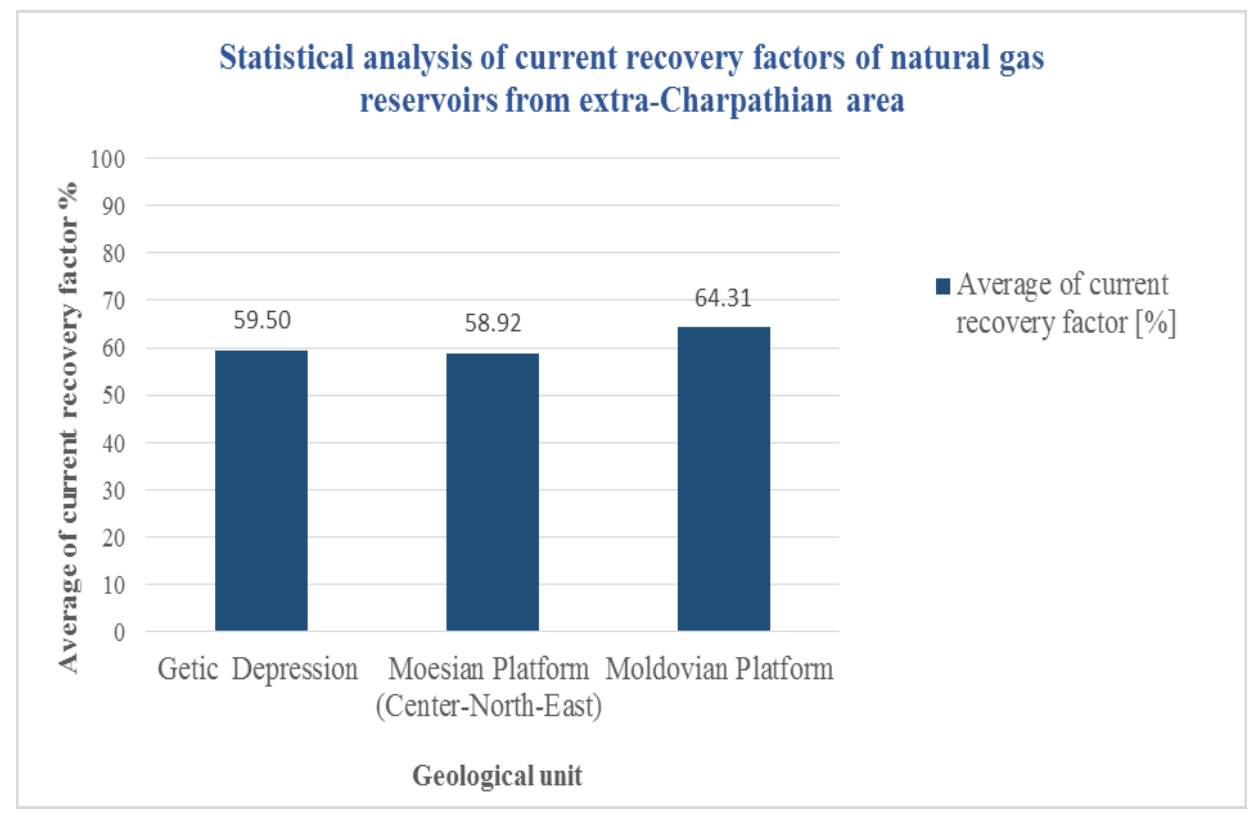

Fig. 6. Graphical representation of statistical analysis related to the current recovery factors of natural gas reservoirs in the Extra-Carpathian area 
Starting a rehabilitation pilot project on a natural gas field is the way forward in the future and based on the results, practices and lessons learned a valuable data base will be outlined which can be useful in the exploitation process of natural gas reservoirs by extending the implementation of rehabilitation concept.

Acknowledgement: The National Gas Company of Romania Romgaz SA.

\section{References}

1. D-P. Stefanescu, Introduction to the mature natural gas reservoir rehabilitation - Theory and case studies (Editura Universitatii Lucian Blaga, Sibiu, 2012).

2. H. Sabri, A. Rahim, et al., Proceedings of the $26^{\text {th }}$ International Business Information Management Association (IBIMA) Conference, (Madrid, Spain, 2015)

3. A.B. Badiru, S.O. Osisanya, Project management for the oil and gas industry (CRC Press, Boca Raton, 2012).

4. https://www.triple-eee.com/news.html (accessed 12.02.3019)

5. D-P. Stefanescu, I.Foidas, Recovery factor and replacement ratio of reserves, key parameters of monitoring the natural process, $17^{\text {th }}$ International Multidisciplinary Scientific Geoconference SGEM, 843-850, 17 (Albena, Bulgaria, 2017).

6. J. O'Brien, L. Sayavedra, J. Mogollon, T. Lokhandwala, R. Lakani, SPE Europec (2016).

7. J.K Forrest, A. Hussain, M. Orozco, T. Bui, R.M. Henson, J.-P. Bourges, M. J. Jalaludin, Proceedings of the International Petroleum Technology Conference (Doha, Qatar, 2009).

8. https://iraq-businessnews.com (accessed 12.02.2019)

9. D. Biedma, C. Corbett, F.Giraldo, et al., Schlumberger Oil Review, 2014, 3 (2014).

10. Offshore Technology, Pequins Field Redevelopment, North Sea, http://offshoretechnology.com (accessed 12.02.2019).

11. http://www.petroleumclub.ro/downloads/Upstream2011/Willie_Toner-Petrofac.pdf (accessed 12.02.2019)

12. https://www.romania-insider.com/omv-petrom-to-spend-eur-400-mln-re-developingolder-oil-fields-in-romania/ (accessed 12.02.2019) 